\title{
Breast Cancer Knowledge among Women in Ebonyi State, Nigeria: Implication for Women Breast Cancer Education
}

\author{
Cajetan Ikechukwu ILO ${ }^{1 *}$, Omaka-Amari ${ }^{1}$, Lois Nnenna ${ }^{1}$, Ignatius Obilor Nwimo ${ }^{1}$ and Chinagorom Onwunaka ${ }^{2}$ \\ ${ }^{1}$ Ebonyi State University, Abakaliki-A 343, Abakaliki, Nigeria \\ ${ }^{2}$ Nnamdi Azikiwe University, Awka onwunaka, Anambra, Nigeria \\ "Corresponding author: Cajetan Ikechukwu ILO, Ebonyi State University, Abakalik-A 343, Abakaliki, Nigeria, Tel: +2348033430522; E-mail: cajetanilo@gmail.com
}

Rec date: Jul 10 2015; Acc date: Jul 23 2015; Pub date: Jul 252015

Copyright: (c) 2015 Ikechukwu CILO, et al. This is an open-access article distributed under the terms of the Creative Commons Attribution License, which permits unrestricted use, distribution, and reproduction in any medium, provided the original author and source are credited.

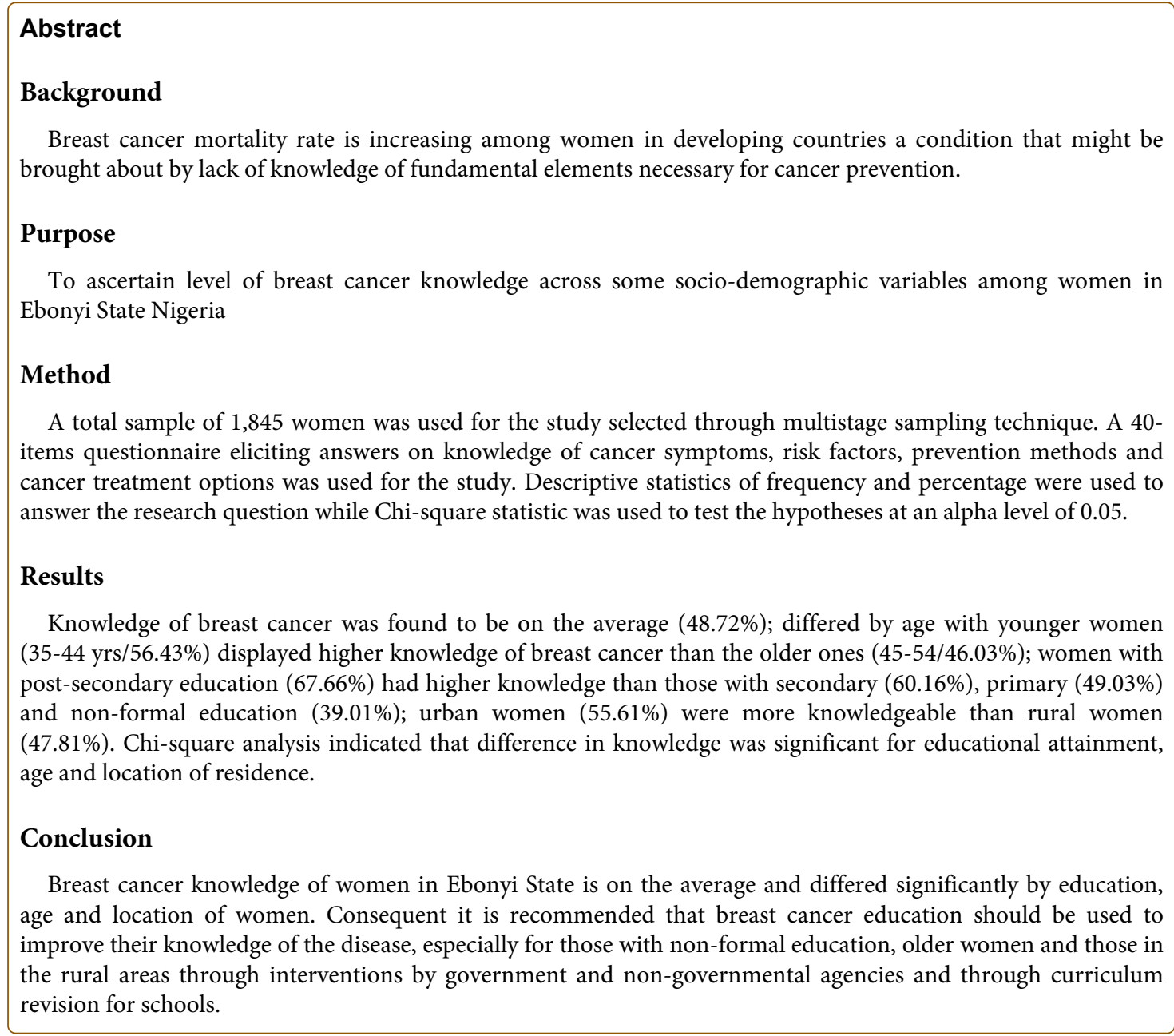

Keywords: Breast cancer; Knowledge; Risk factors; Education; Prevention; Women; Age; Location

\section{Introduction}

Breast cancer is the commonest of all forms of cancer and one of the major threats to health especially among women [1]. Report on the incidence of breast cancer reveals that one out of every eight women in the world stand a chance of having the disease in her life time [2]. Although the incidence of breast cancer is increasing all over the world, the rate of increase is higher in developing countries where late detection of disease is common [3]. Breast cancer is already a well- known health problem in Nigeria with about 1 death in every 25 reported cases [4]. A major worry about breast cancer in Nigeria is the continuous rise in the number of cases and deaths, a situation which confirms Lakeshore Cancer Center prediction that breast cancer cases may rise to 42 million by 2020 in both males and females in the country $[1,5]$.

The primary reason for this increasing mortality rate is due to lack of early detection of disease [6]. This factor is invariably a direct consequence of lack of breast cancer awareness observed in most developing countries. Knowledge about breast cancer is a fundamental element necessary for the early detection, prevention and treatment of 
this condition [7]. Knowledge for this study was considered as the possession of accurate understanding of breast cancer, its symptoms, risk factors, prevention, treatment options and centers. Adequate knowledge of breast cancer will equip women with the ability to observe and identify symptoms before the disease starts to spread and seek medical assistance early; while knowledge of causes and risk factors of cancer will help in the prevention of this disease by equipping to adopt preventive measures and appropriate lifestyle modification.

Breast cancer is essentially preventable. Early detection which remains the surest mean of breast cancer prevention can be achieved through Breast Self-Examination (BSE), Clinical Breast Examination (CBE) and Mammography. The frequency of examination is recommended based on age of women and the type of examination being recommended [8]. Again, several treatment options abound including surgery, chemotherapy, radiotherapy and hormonal therapy which women need to know to make informed choices [6,9-11]. The women also need to know where they can access quality cancer care, which include diagnosis, surveillance and advanced treatment options [12]. A comprehensive knowledge of all these components is important for women since it is the first step to preventing the disease and more so, since the disease is obviously of unknown cause, with non-specific treatment and poor prognosis [13].

Nonetheless, some factors are known to influence breast cancer knowledge among women. These factors include, age, education and location. Studies have shown that knowledge significantly correlated with level of education $[13,14]$. It was observed that women who are educated were more likely to possess satisfactory breast cancer knowledge. Similarly, the disease was found to be more common among women in the urban communities than rural [15]. Although breast cancer occurs frequently among older women, younger women tend to have more knowledge of the disease than the elderly [16].

Statistics indicate rising global incidence of breast cancer and the increase is occurring at a faster rate in developing countries that hitherto enjoyed low incidence of the disease. In Nigeria like in most other developing countries, breast cancer cases are characterized by late presentation of patients at advanced stages of the disease when little or no benefit can be derived from any form of therapy [17]. This trend is quite worrisome and constitutes the stimulus for carrying out this study in Ebonyi State Nigeria, a developing state, which has comparably more illiterate women who live in rural more than urban settlements [18].

The purpose of this study therefore, was to determine levels of breast cancer knowledge among women in Ebonyi State Nigeria and to determine the difference in knowledge by levels of educational attainment, age and location of residence of these women. The study also tested whether the difference in level of knowledge with regard to these socio-demographic variables were significant at 0.05 level of significance.

\section{Methods}

\section{Design and participants}

The cross-sectional survey research design was use for the study. The population of the study comprised 1844496 women aged 35-54 years residing in the thirteen local government areas in Ebonyi State. A sample of 1845 women using the multistage sampling technique was drawn from the thirteen local government areas in the State. This represented less than 1 per cent of the total population of women aged 35-54 years residing in the state.

\section{Instrument}

A self-constructed Women's Breast cancer Knowledge Questionnaire (WBCKQ) was used for the study. The instrument consisted of 40 items spread over sections (A-F). Section A elicited questions on personal data and embodied three questions relating to age, residence of respondent and education qualification. Section B, C, $\mathrm{D}, \mathrm{E}$ and $\mathrm{F}$ included series of items of true and false options covering knowledge about breast cancer symptoms, risk factors, prevention, breast cancer treatment options and breast cancer treatment centers respectively. Face validity of the instrument was determined by three experts in health education. Based on the approval of these experts a final copy of the questionnaire was produced and utilized for data collection. The split half method yielded a reliability coefficient of 0.76 using Spearman Brown correlation.

\section{Analysis}

Out of 1845 copies of the questionnaire distributed, 1843 (99.9\% of those distributed) were found useable. The data collected from each questionnaire were tallied and put into frequencies and simple percentages were used to answer the research questions. Hypotheses were tested using chi-square statistic at an alpha level of 0.05 .

\section{Results}

Table 1 revealed that women's knowledge of breast cancer was average in all the components (symptoms $55 \%$, risk factors $42 \%$, and prevention 57\%, and treatment options 52\%) except for treatment centers $(60 \%)$ were the women demonstrated high knowledge. However, the table showed that women's overall knowledge of breast cancer was average. This is evident in a cumulative grand mean score of 48.72 percent.

\begin{tabular}{|c|c|c|c|c|}
\hline $\mathrm{S} / \mathrm{N}$ & Items & True\% & False $\%$ & Decision \\
\hline \multicolumn{4}{|c|}{ Symptoms } & \\
\hline 1 & Painless lump is a symptom of breast cancer & $981(53)$ & $862(47)$ & Average \\
\hline 2 & Soreness of nipples is a symptom of breast cancer. & 1084(59) & $759(41)$ & Average \\
\hline 3 & Dimpling of the skin of the breast is a symptom of breast cancer. & 986(593) & $857(47)$ & Average \\
\hline 4 & Change in the shape of the breast is a symptom of breast cancer & $953(52)$ & $890(48)$ & Average \\
\hline
\end{tabular}


Citation: Ikechukwu CILO, Amari O, Nnenna L, Nwimo IO, Onwunaka C (2015) Breast Cancer Knowledge among Women in Ebonyi State, Nigeria: Implication for Women Breast Cancer Education. J Health Edu Res Dev 3: 129. doi:10.4172/2380-5439.1000129

Page 3 of 7

\begin{tabular}{|c|c|c|c|c|}
\hline 5 & Redness of the breast is symptom of breast cancer. & $987(54)$ & $856(46)$ & Average \\
\hline 6 & Thickening in the breast is a symptom of breast cancer. & 1085(59) & $758(41)$ & Average \\
\hline \multirow[t]{2}{*}{7} & Wrinkling of the skin of the breast is a symptom of breast cancer & 1010(55) & $833(45)$ & Average \\
\hline & \multicolumn{4}{|l|}{ Overall Risk Factors } \\
\hline 8 & Family history of breast cancer is a risk factor & 1053(57) & $790(43)$ & Average \\
\hline 9 & Induced abortion increases breast cancer risk. & $754(41)$ & 1089(59) & Average \\
\hline 10 & First childbirth after 30 years increases the risk of breast cancer. & 783(42) & 1060(58) & Average \\
\hline 11 & Not having a child increases breast cancer risk & $667(36)$ & $117(54)$ & Low \\
\hline 12 & Menstrual cycle before the age of 12 increases breast cancer risk & $617(33)$ & $1226(67)$ & Low \\
\hline 13 & Alcohol consumption increases the risk of breast cancer. & $867(47)$ & $976(53)$ & Average \\
\hline 14 & Smoking increases the risk of breast cancer. & $729(40)$ & $114(60)$ & Average \\
\hline 15 & Consumption of high fat diet increases risk of breast cancer. & $807(44)$ & 1036(56) & Average \\
\hline 16 & Obesity increases risk of breast cancer. & $763(41)$ & 1080(59) & Average \\
\hline 17 & Poor breast-feeding increases risk of breast cancer. & $649(35)$ & $119(66)$ & Low \\
\hline 18 & Lack of physical activity increases risk of breast cancer. & 809(44) & 1033(56) & Average \\
\hline 19 & Constant use of hair dyes increases risk of breast cancer. & $625(34)$ & 1218(66) & Low \\
\hline 120 & Hurting the breast increases the risk of breast cancer. & $780(42)$ & 1063(58) & Average \\
\hline \multirow[t]{3}{*}{21} & Dense breast tissue increases risk of breast cancer. & $964(52)$ & $879(48)$ & Average \\
\hline & Cumulative Grand Mean Score & $776(42)$ & 1067(58) & Average \\
\hline & \multicolumn{4}{|l|}{ Prevention } \\
\hline 22 & Breast self-examination is a screening method. & $986(53)$ & $857(47)$ & High \\
\hline 23 & Every woman above 20 years should do breast self-examination. & $1106(60)$ & $737(40)$ & High \\
\hline 24 & Breast self-examination is done with the pads of the finger and in a circular motion & 1152(63) & $691(3)$ & Average \\
\hline 25 & Clinical breast examination is a method of breast examination by trained health worker. & $975(53)$ & $868(47)$ & Average \\
\hline 26 & Women 20-39 years should do Clinical Breast Examination once every 2 years. & 1065(58) & $778(42)$ & Average \\
\hline 27 & Women 40 years and above should do Clinical Breast Examination once every year. & $982(53)$ & $861(37)$ & Average \\
\hline 28 & Mammography is the examination of breast lump with a special machine. & $905(49)$ & 938(31) & Average \\
\hline 29 & Mammography utilizes $\mathrm{X}$-rays to detect lump. & 1019(55) & $824(45)$ & Average \\
\hline \multirow[t]{3}{*}{30} & Mammography can reveal early breast lump that Clinical Breast Examination cannot detect. & 1225(66) & $618(34)$ & High \\
\hline & Cumulative Grand Mean Score & $1046(57)$ & $797(43)$ & Average \\
\hline & \multicolumn{4}{|l|}{ Treatment Options } \\
\hline 31 & Breast cancer can be treated with the use of X-ray. & $791(43)$ & 1052(57) & Average \\
\hline 32 & Certain drugs are used for the treatment of breast cancer. & $968(53)$ & $875(47)$ & Average \\
\hline 33 & Certain hormone inhibitors are used to treat breast cancer. & 1045(57) & $798(43)$ & Average \\
\hline 34 & Breast cancer can be treated by surgical removal of lumps. & 1185(64) & $658(36)$ & Average \\
\hline 35 & Removal of affected breast through surgery can cure breast cancer & 1002(54) & $841(46)$ & Average \\
\hline
\end{tabular}


Citation: Ikechukwu CILO, Amari O, Nnenna L, Nwimo IO, Onwunaka C (2015) Breast Cancer Knowledge among Women in Ebonyi State, Nigeria: Implication for Women Breast Cancer Education. J Health Edu Res Dev 3: 129. doi:10.4172/2380-5439.1000129

Page 4 of 7

\begin{tabular}{|c|c|c|c|c|}
\hline 36 & Removal of the entire breast and tissues under the arm can treat breast cancer. & $736(40)$ & $1107(60)$ & Average \\
\hline & Cumulative Grand Mean Score & $955(52)$ & $888(48)$ & Average \\
\hline & \multicolumn{4}{|l|}{ Treatment Centers } \\
\hline 37 & Breast cancer can be diagnosed and treated in Specialist Hospitals. & 1085(59) & $758(41)$ & Average \\
\hline 38 & General hospitals cannot diagnose and treat breast cancer. & 1065(59) & $758(41)$ & Average \\
\hline 39 & Breast cancer cannot be diagnosed and treated in herbal homes. & $954(52)$ & $669(48)$ & Average \\
\hline \multirow[t]{3}{*}{40} & Breast cancer special centers can diagnose and treat breast cancer. & $126(59)$ & $580(31)$ & High \\
\hline & Cumulative Mean Score & 1097(60) & $746(40)$ & High \\
\hline & Cumulative grand mean score & $898(48.72)$ & $945(51.28)$ & Average \\
\hline
\end{tabular}

Table 1: Frequency, Percentage Distribution of Response on Knowledge of Breast Cancer (N=1843).

Table 2 indicated that women with post-secondary education demonstrated an overall better knowledge of breast cancer with a percentage score of 67.66, followed by women with secondary education, primary (49.34\%), and non-formal education (39.01\%). The table also revealed that there was a significant difference in knowledge of breast cancer amongst the women by their levels of educational attainment.

\begin{tabular}{|c|c|c|c|c|c|c|c|c|c|}
\hline $\mathrm{S} / \mathrm{N}$ & Items & Non-formal Edu (922) & $\begin{array}{l}\text { Prim. Edu } \\
(n-76)\end{array}$ & $\begin{array}{l}\text { Sec. Edu } \\
(n-516)\end{array}$ & Post.Sec Edu (n-329) & $x^{2} \mathrm{cal}$ & $x^{2}$ crit & Df & Dec \\
\hline & & $\begin{array}{l}\text { \%Correct } \\
\text { Response }\end{array}$ & $\begin{array}{l}\text { \%Correct } \\
\text { Response }\end{array}$ & $\begin{array}{l}\text { \%Correct } \\
\text { Response }\end{array}$ & $\begin{array}{l}\text { \% Correct } \\
\text { Response }\end{array}$ & & & & \\
\hline 1 & Symptoms & 37.68 & 56.39 & 64.59 & 74.42 & & & & \\
\hline 2 & Risk Factors & 34.41 & 40.41 & 47.76 & 55.43 & & & & \\
\hline 3 & Prevention & 42.83 & 57.89 & 69.08 & 76.22 & & & & \\
\hline 4 & Treatment Options & 37.82 & 48.03 & 65.31 & 72.14 & & & & \\
\hline 5 & Treatment Center & 50.62 & 50.99 & 68.07 & 72.95 & & & & \\
\hline \multicolumn{2}{|c|}{ Grand Mean } & 39.01 & 49.34 & 60.16 & 67.66 & 102.731 & 7.82 & 3 & $\mathrm{~S}^{*}$ \\
\hline
\end{tabular}

Table 2: Descriptive Statistics and Chi-square Analysis on Level of Breast Cancer Knowledge among Women in Ebonyi State Based on Level of Education $(\mathrm{N}=1843){ }^{*} \mathrm{~S}=$ Significant at $\mathrm{p}<0.05, \mathrm{DF}=3$, Calculated value $=102.731$, Critical value $=7.82$.

Table 3 showed that younger women displayed better cognition of breast cancer components compared (symptoms 59.32\%, risk factors $45.58 \%$, prevention $68.68 \%, 57.45 \%$, and $60.43 \%)$ to older women (symptoms $49 . \%$, risk factors $45.58 \%$, prevention $68.68 \%, 57.45 \%$, and $60.43 \%)$. This is evident in a grand mean score of 56.43 percent for younger women (35-45) compared to 46.03 percent score for older women (45-54). Table 3 also indicated that there is significant difference in knowledge of breast cancer among women in Ebonyi State Nigeria by age.

\begin{tabular}{|c|c|c|c|c|c|c|c|}
\hline$S / N$ & Items & $\begin{array}{l}35-45 \text { yrs } \\
(\mathrm{n}-977)\end{array}$ & $\begin{array}{l}45-65 \text { yrs } \\
(n-866)\end{array}$ & $\times 2$ cal & $x^{2}$ crit & Df & Dec \\
\hline 1 & Symptom & 59.32 & 49.97 & & & & \\
\hline 2 & Risk Factors & 45.58 & 38.22 & & & & \\
\hline 3 & Prevention & 68.68 & 49.96 & & & & \\
\hline 4 & Treatment option & 57.45 & 45.32 & & & & \\
\hline 5 & Treatment Centers & 60.26 & 58.69 & & & & \\
\hline
\end{tabular}


Citation: Ikechukwu CILO, Amari O, Nnenna L, Nwimo IO, Onwunaka C (2015) Breast Cancer Knowledge among Women in Ebonyi State, Nigeria: Implication for Women Breast Cancer Education. J Health Edu Res Dev 3: 129. doi:10.4172/2380-5439.1000129

Page 5 of 7

\begin{tabular}{|l|l|l|l|l|l|l|}
\hline Grand Mean Score & 56.43 & 46.03 & 14.65 & 3.481 & 1 & S \\
\hline
\end{tabular}

Table 3: Descriptive Statistics and Chi-square Analysis on Breast Cancer Knowledge among Women in Ebonyi State Based on Age ${ }^{\star}(\mathrm{N}=1843)$. Significant at $\mathrm{p}<0.05, \mathrm{DF}=1$, Calculated value $=14.65$, Critical value $=3.48$.

Summary of data analysis on Table 4 revealed that urban women with average score of $55.61 \%$ demonstrated higher knowledge of breast cancer than the rural women with an average score of 47.81 percent.
Table 4 further indicated that urban and rural women in Ebonyi state differ significantly in their knowledge of breast cancer.

\begin{tabular}{|c|c|c|c|c|c|c|c|}
\hline $\mathrm{S} / \mathrm{N}$ & Items & Urban & Rural & X2 cal & $X 2$ crit & $\mathrm{Df}$ & Dec \\
\hline 1 & Symptom & 59.45 & 52.67 & & & & \\
\hline 2 & Risk Factors & 49.90 & 37.66 & & & & \\
\hline 3 & Prevention & 60.59 & 55.57 & & & & \\
\hline 4 & Treatment option & 51.68 & 51.84 & & & & \\
\hline \multirow[t]{2}{*}{5} & Treatment Centers & 63.64 & 57.45 & & & & \\
\hline & Grand Mean Score & 55.61 & 47.81 & 9.392 & 3.841 & 1 & $\mathrm{~s}$ \\
\hline
\end{tabular}

Table 4: Descriptive Statistics and Chi-square Analysis on Breast Cancer Knowledge by Location of Residence* of Women in Ebonyi State $(\mathrm{N}=1843){ }^{*}$ Significant at $\mathrm{p}<0.05, \mathrm{DF}=1$, Calculated value $=9.392$, Critical value $=3.841$

\section{Discussion}

Findings in Table 1 revealed that generally, women in Ebonyi State had average knowledge of all the components of breast cancer. This result disagrees with the popular opinion that women in developing countries like Nigeria have poor knowledge of the disease $[6,19]$. Fregene and Newman observed that even among the most affluent Nigerian, breast cancer awareness tends to be relatively low in their list of health care priorities [20]. Findings also disagree with those of Oluwatosin, and Oladipo, which reported that women lacked knowledge of vital issues about breast cancer and early detection measures [21]. In this study it was upheld that community-dwelling women in Ebonyi State, Nigeria have rather poor knowledge of breast cancer

Nonetheless, this result might have been accounted for by the aggressive campaign mounted by some Non-governmental Organization (NGOs) through women meetings and other such gatherings. For instance, the Ebonyi State Medical Doctors Wife Association mounted Breast Cancer Campaign since 2005, the ongoing Maternal and Child Care Programme mounted and sustained by the wife of Ebonyi State Governor and other interventions as reported in Omaka [22].

Summary of results in Table 2 revealed that education was a strong determinant of knowledge of breast cancer among the women. It was observed that women with post-secondary education in almost all the items had higher knowledge than women with secondary, primary and non-formal levels of education respectively. This result collaborated those of Ozturk, Engin, Kisioglu and Yilmazer which reported that women who graduated from secondary school were 22 times more likely to know and 3 times more likely to perform BSE than others [14]. In the same light Okobia, Bunker, Okonofua and Osime reported that women with higher level of education were significantly more knowledgeable about breast cancer than other women [17].
Result in Table 3 indicated that age had significant influence on knowledge of breast cancer symptoms, risk factors, preventive measures, treatment options and treatment centers respectively. For most of these items, younger women (35-44) had higher knowledge than the older ones (45-54). These findings are not surprising since they agree with most related studies. For instance Self and Aziz reported that women participants less than 40 years, were found to have higher percentage (22.7 percent) of satisfactory knowledge preprogram, than those aged 40 years and above (10.6\%) [13]. Grunfeld, Ramirez, Hunter, and Richard also reported that older women were particularly poor at identifying symptoms of breast cancer, risk factors associated with breast cancer and their personal risk of developing the disease. Poor breast cancer knowledge among older women they observed may help to explain the strong association between older age and delay in seeking help. In the same light, Fregene and Newman observed that breast cancer case ascertainment is low among older African women because of their lower literacy rates, poor socioeconomic status, and diminished awareness of breast cancer [20].

Result in Table 4 indicated that there is difference in the level of knowledge of breast cancer among urban and rural women. This is in line with the observations of Fregene and Newman that understanding and awareness of breast cancer is particularly low within the general population of Africa outside of urbanized areas [20]. Oluwatosin and Oladipo also reported that majority of rural women were not aware of early warning signs of breast cancer and only $1.9 \%$ acknowledged a painless lump as an early warning sign [21]. The overall knowledge of treatment of breast cancer was also very poor. However the reason for the disparity in the knowledge of breast cancer between urban and rural women in the present study may be drawn from the opinion of Pheby that Breast cancer is more common in the urban than rural areas [15]. Hoffman et al. also observed a doubling of breast cancer incidence rates in women living in urban areas compared with those residing in the rural [23]. In general high incidence of a disease increases it awareness among community members. It is a common 
knowledge that urban dwellers in general have more access to health and media services which according to Yucel, Dekremen, Acar, Elldokuz, Albayrak, and Haktanir may enhance their knowledge of health issues especially those occurring in the community [24]. In most rural communities in Nigeria health and media facilities and services are limited, thus rural women are less likely to have adequate knowledge of health information.

\section{Implication for breast cancer education among women}

The finding that the women had average knowledge (40-59\%) breast cancer, translates to the fact that a good percentage of still lack accurate information concerning the disease, especially in the area of risk factors where the percentage scores range from $33-47 \%$. It is expected that for a disease like breast cancer a high percentage of knowledge is required among the women in order to identify and promptly stop the progression of the disease. Jones et al. observed that adequate knowledge of breast cancer risks especially the role of family and personal history is significantly related to screening behaviour [16]. This implies therefore, that there is a critical need to educate women about breast cancer to improve their knowledge and mounting of effective intervention programmes for dealing with the consequences of breast cancer.

The finding that younger woman have higher knowledge than the older ones is not a cheering situation and has implications for breast cancer prevention and control. This is because breast cancer is predominantly an age-related disease occurring more in older population than younger ones $[25,26]$. Similarly with respect to the disparity in knowledge across educational levels, findings imply that majority of the women with non-formal and primary education, do not have adequate knowledge of the disease. This is also the case with women in the rural areas. These findings have serious implications on the prevention and control of breast cancer which current data suggest is already in the increase in the Nigeria [18].

\section{Conclusions}

Women in Ebonyi State have inadequate knowledge of breast cancer. However knowledge of breast cancer significantly differs among women of diverse educational backgrounds, age and location. Breast cancer knowledge was higher among those with higher levels of education, younger women and women who live in the urban areas. However there is need for improved breast cancer education intervention to enhance women's breast cancer knowledge in the State

\section{Recommendations}

Based on the findings of this study the following recommendations are made:

Health workers should embark on intensive breast cancer education programmes with emphasis on early detection of symptoms and personal risk assessment through the instrumentality of health care providers and through community based organizations like women associations.

There is also need to maximize the use of the mass-media in the dissemination of cancer education especially through radio and television which enjoy higher listenership.

Programmes for breast cancer education should be mounted for women in the state to improve their knowledge especially for rural women, women with non-formal level of education as well as older women (44 years and above). This can be achieved by designing programmes which specifically target these disadvantage segments of society.

Government should sponsor the integration of breast cancer education into the health education curriculum from an early stage of education and at every level of education to improve the knowledge of the masses through the educational system.

\section{References}

1. Lakeshore cancer center (2014) Breast cancer awareness. March 19th, 2015.

2. American cancer society (2015) Breast cancer. March 19th, 2015.

3. WHO (2015) Breast cancer prevention and Control. March 19th, 2015.

4. Olaleye F (2013) One in every 25 Nigeria women dies of breast cancerexpert. March 19th, 2015.

5. Cancer Epidemiology (2012) Cancer incidence in Nigeria: A report from population based cancer registries. Cancer Epidemiology 36: 271-278.

6. Badar F, Faruqui ZS, Ashraf A, Uddin N (2007) Third world issues in breast cancer detection. Journal of Pakistani Medical Association, 57: 137-40.

7. Outlook (2002) Breast cancer: Increasing incidence, limited options. Retrieved June 12, 2006 Volume 19.

8. Modeste NN, Caleb-Drayton VL, Montgomery S (1999) Barriers to early detection of breast cancer among women in a Caribbean population. Pan-American Journal of Public Health, 5: 152-156.

9. Richard A, McCartney MD, Teresa GO (2004) Breast cancer. Gale Encyclopedia of Medicine.

10. Simon H (2002) Breast cancer. Well-connected reports, Harvard medical School, Massachusetts General Hospital.

11. Agha EM, Duroshola M (2002) Pregnancy, Menopause and Breast cancer: A Counseling Guide for women. Enugu: Cheston Ltd.

12. Stanford Comprehensive Cancer Center (2006) Breast cancer. March 11 th 2007.

13. Seif NY, Aziz M (2000) Effect of breast self-examination training programme on knowledge, attitude and practice of a group of working women. Journal of the Egyptian National Cancer Institute 12: 105-115.

14. Ozturk M, Engin VS, Kisioglu AN, Yilmazer G (1999) Effects of education on knowledge and attitude of breast self-examination among 25+ years old women. Eastern Journal Medicine 5: 13-7.

15. Pheby D (2002) Breast cancer current trends and future hopes. Positive Health, Complementary Health Magazine.

16. Jones AR, Thompson C J, Oster RA, Samid A, Davis MK, et al. (2003) Breast cancer knowledge, beliefs and screening behaviors among lowincome elderly black women. Journal Of Medical Association 95: 791-7, 802-5.

17. Okobia MN, Bunker CH, Okonofua FE, Osime U (2001) Breast cancer Knowledge, attitude and practice of Nigerian women towards breast cancer, a cross-sectional study. World Journal of Surgical Oncology 4: 1.

18. Ebonyi State House of Assembly (2006) Dairy. Abakaliki: A Publication of the State Ministry of Information.

19. Okobia MN (2003) Cancer care in sub-Sahara Africa-Urgent need for population based cancer registries. Ethiopian Journal of Health Development 17: 89-98.

20. Fregene A, Newman LA (2005) Breast cancer in sub-Saharan Africa: How does it relate to cancer in Africa American women? Cancer 103: 1540-1550.

21. Oluwatosin OA, Oladipo O (2006) Knowledge of breast cancer and its early detection measures among rural women in Akinyele LGA, Ibadan Nigeria. BMC Cancer 6: 271.

22. Omaka Amari LN (2004) The teaching of health education in schools: A necessary foundation for nation building. Health and Movement Education Journal 8: 76-82. 
Citation: Ikechukwu CILO, Amari O, Nnenna L, Nwimo IO, Onwunaka C (2015) Breast Cancer Knowledge among Women in Ebonyi State, Nigeria: Implication for Women Breast Cancer Education. J Health Edu Res Dev 3: 129. doi:10.4172/2380-5439.1000129

Page 7 of 7

23. Grunfeld EA, Ramirez AJ, Hunter MS, Richard M A (2002) Women's knowledge and beliefs regarding breast cancer (age as a factor). British Journal of Cancer 86: 1373-8.

24. Hoffman M, de Pinho H, Cooper D, Sayed R, Dent DM et al. (2000) Breast cancer incidence and determinants of cancer stage in the Western Cape. South African Medical Journal 90: 1212-1216.

25. Yucel A, Dekremen B, Acar M, Elldokuz H, Albayrak R (2005) Knowledge about breast cancer and mammography in breast cancer screening among women awaiting mammography. Turkey Journal Of Medical Science 35: 35-42.

26. Tamimi RM, Byrne C, Colditz GA et al. (2007) Endogenous Hormone Levels, Mammographic Density and Subsequent Risk of Breast Cancer in Postmenopausal Women. Journal of National Cancer Institute 99: 1178-87. 